Aufschliessung der Silicate mit Fluorammonium, in Fällen, in denen auf Alkalien Rücksicht genommen werden soll.

Von

Prof. Dr. Robert Hoffmann in Prag.

Die Aufschliessung von durch Säuren unzersetzbaren Silicaten, in Fällen, in denen auf Alkalien Rücksicht genommen werden soll, hat bekanntlich nicht geringe. Schwierigkeiten, und alle die in dieser Beziehung in Forschlag gebrachten Methoden lassen sehr viel zu wünschen ubrig. So verlangt das Aufschliessen mit koblensaurem Kalk oder Baryt eine selr bedeutende Hitze, die hervorzubringen eben nicht in jedem Laboratorium möglich ist. Bei dieser Gelegenheit sei bemerkt, dass es mir nie gelungen 1 Theil Silicat mit 0,8 Theilen kohlensaurem Baryt bei mässiger Glühhitze zum Schmelzen zu bringen, wie Deville angibt. Bei gleichen Gewichten von kohlensaurem Baryt and Silicat war immer 2-3-stündiges sehr heftiges Glühen in einem sehr guten Windofen erforderlich. Nebstdem hat diese Aufschliessung bei grossen Mengen von kohlensaurem Baryt eine immerhin mögliche Austreibung der Alkalien durch das sich bildende Baryumoxyd gegen sich. Eine Zugabe von Chlorbaryum zum kohlensauren Baryt, wie Smith anempfohlen, erscheint desshalb nicht rathsam, weil sich beim Schmelzen Chloralkalimetalle bilden, welche bei hoher Hitze flüchtig sind: Aus gleichem Grunde erscheint die Zugabe von Salmiak beim Aufschliessen mit kohlensaurem Kalke- verwerflich, indem sich Chlorcalcium bildet, das beim Glühen mit Alkalien zur Bildung von Chloralkalimetallen Veranlassung gibt. In neuerer Zeit wendet man meist Flusssäure und zwar im flüssigen Zustande an, weil das Aufschliessen mit gasförmiger Säure nach Brunner's Angabe nicht nur in der Ausführung anf grosse Hindernisse stösst, sondern auch eine für die Gesundheit äusserst gefährliche Operation ist. Hat man das Silicat nicht ungemein fein gepulvert, setzt man es nieht in änsserst dünner Lage der Einwirkung der Flusssänredämpfe aus, und rührt man dasselbe nicht öfter auf, so gelingt das Aufschliessen nicht, und selbst bei Berücksichtigung aller dieser Umstände findet man nur zu oft nach Behandeln mit Salzsäure noch unzersetztes Silicat. Beim Umrühren der Substanz und beim Uebergiessen des Flussspathes mit Schwefelsänre ist es kaum möglich sich vor Flasssäuredämpfen zu schützen. Die Verwendung der wässe- 
rigen Flussäure ist in allen diesen Beziehungen vorzuziehen, das Aufschliessen gelingt viel leichter. Ich wende nun schon seit längerer Zeit anstatt der wässerigen Flusssäure das Fluorammonium mit Schwefelsäure mit bestem Eríolge an, weil mir diese Aufschliessung mit festom Fiuorammonium noch vortheilhafter als erstere erscheint*). Ich verfahre in folgender Art: Das sehr fein gepulverte Silicatpulver wird mit dem 3-4-fachen Gewichte von vollkommen reinem Fluorammonium gemischt in eine Platinschale gebracht, mit Schwefolsäure ganz durchfeuchtet und dann ganz mässig, am besten im Wasserbade, erhitzt, wobei die nöthigen Vorsichtsmaassregeln wegen der sich entwickelnden Dämpfe von Kieselfuor und Fluorwasserstoff and des Verspritzens nicht ausser Acht zu lassen sind. Nach einiger Zeit, wenn die Entwickelung der Dämpfe nachgelassen, befeuchtet man nochmals mit Schwefelsäure und erhitzt dann so lange und zwar zuletzt uber der freien Flamme, bis die Masse ganz trocken geworden und alle freie Schwefelsäure verflüchtigt ist. Der Räckstand wird mit Salzsäure digerirt, in welcher er sich vollkommen lösen muss, wenn die Aufschliessung ganz erfolgt und Baryt nicht vorhanden ist. Bei Gegenwart von Kalk erfolgt die Lösung erst nach längerer Zeit. Will man mur die Alkalien bestimmen, so fällt man am zweckmässigsten mit Ammoniak und kohlensaurem Ammoniak die übrigen Basen bis auf Magnesia aus, wenn diese vorhanden, aus dem Filtrate weiter die Schwefelsäure mit einem möglichst geringen Ueberschuss von Chlorbaryum

*) Ich erinnere bei dieser Gelegenheit daran, dass das Fluorammonium zum Aufschliessen der Silicate so weit mir bekannt anerst von L. von Babo empfohlen worden ist (Amtlicher Bericht über die zwanzigste Versammlung der Gesellschaft deutscher Naturforscher und Aerzte zu Mainz 1842, S. 103). Nach der dort gemachten Angabe wurde die Methode für quantitative Analysen noch nicht vollkommen genügend befunden, indem sich immer $1-2$ Proc. des Minerals der Zersetzung entzögen. Später ist das Fluorammonium von H. Rose (Pogg. Annal. 108. 20) und von J. Potyka (Untersuchungen über einige Fineralien, Inauguraldissertation; Berlin 1859. 38) empfohlen worden. Von Beiden wird angegeben, dass die Siicate durch Fluorammonium leichter als durch Fluorwasserstofisäure zersetzt würden. Während von Babo nach Zusatz des Flnorammoniums und nach freiwilligem Verdunsten des Ammoniaks sofort Schwefelsäure zufügt, lässt $H$. Rose das feingepulverte Silicat mit der sechsfachen Menge Fluorammonium und etwas Wasser erst gelinde erwärmen, dann allmählich zum Rothglithen erhitzen bis sich keine Dämpfe mehr entwickeln, und dann erst den Rückstand mit Schwefelsäure behandeln. 
und dampft die vom schwefelsauren Baryt abfiltrirte Lösung unter Zugabe von Oxalsäure ein, glüht und nimmt mit Wasser auf, wodurch die Alkalien in Lösung übergehen*). Sie sind i $\mathrm{mmer}$ noch auf etwa durch Ammon and kohlensaures Ammoniak nicht gefällte Basen zu prüfen, zu welchem Behufe man die Lösung der kohlensauren Alkalien zur Trockene eindampft und mit wenig Wasser aufnimmt, in welchem sie sich vollkommen lösen müssen.

Natürlich muss das zum Aufschliessen in Verwendung kommende Fluorammonium ganz frei von Alkalien sein; es darf in einem Platingefäss' erhitzt keinen Rückstand binterlassen. Wie es im Handel vorkommt ist es fast nie frei von Alkalien, namentlich Natron, indem es unbegreiflicher Weise in Glasgefüssen versendet und aufbewahrt wird. Am besten ist es in mit Wachs oder Paraffin getränkten Holzgefässen oder Kautschukbüchsen $z u$ bewahren. Hat man es mit unreinem Fluorammonium zu thun, so reinigt man sich dasselbe durch Sublimation zwischen Platinschalen.

\section{Ueber quantitative Bestimmung der fetten Oele.}

Von

\section{Demselben.}

Die Bestimmung der fetten Oele beruht bekanntlich auf ihrer Extraction durch Aether oder anderen leicht flüchtigen Lösungsmitteln derselben, indem nach geschehener Entfettung und Verflüchtigung des betreffenden Lösungsmittels das Oel im Rückstande bleibt und als solches gewogen wird. Ich fasse in dieser Beziehung als Lösungsmittel Aether, Schwefelkohlenstoff und Benzin ins Auge. Vorerst muss jedoch hervorgehoben werden, dass diese Methode der Oelbestimmung auf wissenschaftliche Genauigkeit natürlich keinen Anspruch macht, indem durch genannte Lösungsmittel überhaupt alle jene Stoffe, die man unter dem Namen ,F e tte $e^{6}$ zusammenfasst, ferner mehr oder weniger Chlorophyll, Wachs ${ }^{* *}$ ) und viele andere Substanzen, gelöst werden. Eine Ab-

;) Anleitung zur quantitativen Analyse von R. Fresenius. 5. Auf. S. 446.

**) Namentlich durch heissen Schwefelkohlenstoff. 